\title{
Feasibility Data of Traditional Sports Industrialization Development and Informatization Development Based on Big Data
}

\author{
Sun Jiaji ${ }^{1}$ and Li Yuezhong ${ }^{1, *}$ \\ ${ }^{1}$ Physical Education Department, Guangzhou College of Commerce, Guangzhou, China \\ $1,{ }^{*}$ College of Physical Education and Health, Guangzhou University of Chinese Medicine, Guangzhou, China
}

\begin{abstract}
Since the reform and opening up, China's economy has been developing rapidly and the material living standard has been improving continuously. People begin to pay more attention to the mental and physical health. Therefore, more and more people take part in a variety of sports activities to exercise their body and watch large-scale sports events to cultivate the sports spirit. These changes have boosted the development of China's sports industry, which is reflected in the continuous expansion of the scale of the sports industry, the deepening of the degree of industrial segmentation and the continuous innovation of the development concept. This paper mainly studies the feasibility data analysis of traditional sports industrialization development and informatization development based on big data. In this paper, by using the research methods of literature, observation, field investigation and logical analysis, the industrialization development of traditional sports is deeply studied and systematically combed. From the perspective of informationization, this paper makes an in-depth analysis of the current situation, existing problems, the importance of industrialization, and the advantages of industrialization of traditional sports, and makes a detailed exploration and elaboration of the opportunities brought by informatization to traditional sports industry and the development strategies of the industrialization of traditional sports in the future.
\end{abstract}

\section{Introduction}

In recent decades, with the rapid development of information technology in the world, the information economy has played a huge role in promoting the growth of the world economy, and the information industry derived from the information economy has become a major trend of the world economic development. Moreover, the information industry development level of high and low all over the world not only reflect the level of economic development, become the international competitiveness of key decided to national economy, mainly manifested in, information level of economic development is not only an important factor in the development of, and its influence has expanded military, politics, economy, population, land, culture, etc. [1]. From producing to sports industry begun to take shape has one hundred years of history, in the process of the development of integrated and complementary industries, these industries into the information in the environment of economic development and prosperity of the scene (such as information industry and tourism, clothing, transportation, electronics, construction and insurance industries together). In the modern society, sports popularity in many countries more and more high, along with the rapid development of economic globalization modern sports has become an indispensable important part of economic growth in many countries, led to constantly strengthen the importance of sports and investment, to to promote the sports industry to equal status with the national major economic industry [2]. After the 1980s, China's sports industry has been booming, not only to meet the growing demand for sports and fitness of the public, but also to help promote the development of China's economy, so that the development of the sports industry is more and more in line with the development requirements of the new century market economy. The huge economic potential of the sports industry has attracted the attention of the world, and its huge economic potential is expected to make the development of modern sports become a new normal to drive the global economy [3]. Therefore, it is feasible to develop the "fertile land" of traditional sports from the field of information economy.

The concept of sports industry in academic circles is not consistent, and the theoretical researchers of sports industry in various countries and regions have defined the concept of sports industry respectively according to their own local development model of sports industry. The viewpoints of theoretical researchers can be basically divided into two categories: one is the concept of sports industry in a broad sense, and the other is the concept of sports industry in a narrow sense [4]. In the broad sense, scholars believe that the sports industry refers to the sports equipment, facilities and supplies

"Li Yuezhong': 3531501@qq.com 
produced by economic subjects to meet the needs of the public, as well as services such as leisure fitness and competition performance [5]. In a narrow sense, scholars believe that the sports industry refers to the leisure and fitness services provided by market subjects for the public, that is, the sports service industry which belongs to the tertiary industry of the national economy is the sports industry [6].

This paper studies the feasibility of the development of traditional sports industrialization from the perspective of informationization, sports industry and information economy. It is of great significance to protect and inherit the intangible cultural heritage of traditional sports and promote the extensive and sustainable development of national fitness movement.

\section{Feasibility of Industrial Development and Informatization of Traditional Sports}

\subsection{Dynamic elements of sports industry development}

High-quality development of sports industry includes internal driving factors and external driving factors, and the correlation and coupling relationship between them and internal factors is the basis for promoting high-quality development of sports industry [7]. The internal driving factors mainly reflect the changes of the supply side and demand side of the sports industry. The external driving factors mainly reflect the changes of industrial ecological environment. From the perspective of power, the high-quality development of the sports industry should be promoted through the drive of product production and demand consumption, namely, the two ends of the demand side and the supply side [8-9]. Manpower, capital, science and technology, information and intellectual property are important supporting elements for the high-quality development of sports industry [10].

\subsubsection{Internal driving force}

$\mathrm{NaQuDongLi}$ elements of high quality sports industry development is the core content of dynamic mechanism, including the traction on the production side supply driver, consumption demand and human, capital, technology, intellectual property information of elements such as support and impetus, traction and support the development of high quality stereo NaQuDongLi sports industry. Production factors refer to the sports products or services provided by producers to the public, while consumption factors are to meet and stimulate the public's demand for sports products or services [11].

\subsubsection{External driving force}

The external driving factors of the development of sports industry are the important basis of the dynamic mechanism, including the market and the government.
On the one hand, the traction of the economic level generates the support of the market environment; on the other hand, the impetus of the government administration generates the support of the industrial policy. The market environment and the industrial policy interact and influence each other, together constitute the external driving factors for the development of sports industry [12].

\subsection{Feasibility of information development of sports industry}

\subsubsection{Increasing demand for public sports}

At present, the Chinese government is in an important period of transformation from a management-oriented government to a service-oriented government. It is an inevitable trend for the government to streamline administration and delegate power and guide the common development of various subjects. The same is true for the development of sports industry. Sports industry is not only a new growth point of national fiscal revenue, but also an activity carrier to meet people's spiritual and cultural needs. In the process of providing sports industry public services, we should not only rely on the direct production of public sports products by the government to provide sports industry public services, but advocate the implementation of the government-enterprise-social organization, which is a diversified supply model. Government should from previously at the head of the global "omnipotent government" to "government", that is, from production provides all of the sports industry, the public service government to focus on research services policy formulation and modification of the government, from the macro management of public services, sports industry related trivia to the relevant enterprises and social organizations to complete. In this way, the government needs to strengthen communication with enterprises and social organizations, keep an eye on the changes in the sports market, and constantly formulate and improve policies related to the sports industry according to the actual needs. The construction of sports industry informatization promotes the transformation of national sports industry management to a certain extent and meets the transformation needs of government departments.

For enterprises, they are the audience of industrial services, but in this government-enterprise-social organization supply mode, it also plays the role of producer providing sports industry quasi-public services. In order to make profits, an enterprise must strengthen its own strength to compete with other enterprises, which will make it necessary to provide better quality and more efficient services. Sports industry informatization can reduce the cost of enterprise development, improve the efficiency of enterprise management, and enhance the competitiveness of enterprise development.

The third sector is different from enterprises in that it does not aim at making profits. It is an organization with a certain public welfare purpose, just like the 
government. Where the government has no control over specific sports industry public services, these social organizations are good at it. Using these social organizations can assist the government to complete the micro aspects of public service work. Sports industry informatization is equivalent to the work place established by government departments for the third sector to carry out sports industry work, which enables the third sector to have certain resources and authority to manage the development of sports industry and meet the desire of the third sector to play a practical role.

At the same time, many people began to participate in the development of sports industry from the initial participation in physical exercise because of their love for sports or optimistic about the future development prospects of sports. The public's increasing demand for public service in sports industry also provides the possibility for the construction of sports industry informatization.

\subsubsection{The continuous development of computer technology provides a guarantee for it}

Advantages of large-scale data mining. With the development of the sports industry and the increase of industrial activities, massive amounts of information and data will be generated, and the sports industry will gradually enter the era of big data.

Cloud security advantages. The development of sports industry will produce many kinds of information, including the secret information of the government, enterprises and social organizations. The disclosure of these secret information is likely to make them suffer heavy losses. Cloud platform is through the use of tens of thousands of clients to the network anomaly behavior monitoring software, and have found that has pushed to the hidden trouble of program information server carries on the analysis and processing, and then send the handle carry virus software solutions to to each client, the Internet is a powerful anti-virus capabilities. This can well solve the information security problems of the government, enterprises and sports social organizations in the cloud platform, and promote the smooth progress of work activities on the cloud platform of the sports industry.

\section{Investigation on the Development of Sports Industry in a Province}

\subsection{Literature Method}

According to the purpose and content of the research, the relevant literature and regulations of the sports industry were collected and consulted to grasp the current situation and trend of the relevant research. Through searching and studying the collected literature and regulations, this paper analyzes their common characteristics and individual characteristics, so as to find out the problems existing in the theory and practice of the driving mechanism for the development of sports industry, and sort out the direction and thinking of the research.

\subsection{Field Investigation Method}

For sports industry development, such as the construction of dynamic mechanism and path, the province and part of the competent department of city sports industry, sports market main body to carry out on-the-spot investigation, the main problems existing in the development of sports industry research and analysis, the main reasons for the problems for the proposed dynamic mechanism of the high quality sports industry development in China lay the foundation.

\subsection{Mathematical Statistics}

In this paper, SPSS 22.0 software was used to statistic and analyze the collected data, and t-test was carried out. The t-test formula used in this paper is as follows:

$$
\begin{gathered}
\mathrm{t}=\frac{\overline{\mathrm{x}}-\mu}{\frac{\sigma \mathrm{X}}{\sqrt{\mathrm{n}}}} \\
\mathrm{t}=\frac{\overline{\mathrm{X}_{1}}-\overline{\mathrm{X}_{2}}}{\sqrt{\frac{\left(\mathrm{n}_{1}-1\right) \mathrm{s}_{1}^{2}+\left(\mathrm{n}_{2}-1\right) \mathrm{S}_{2}^{2}}{\mathrm{n}_{1}+\mathrm{n}_{2}-2}\left(\frac{1}{\mathrm{n}_{1}}+\frac{1}{\mathrm{n}_{2}}\right)}} \\
\mathrm{t}=\frac{\overline{\mathrm{d}}-\mu_{0}}{\mathrm{~s}_{\mathrm{d}} / \sqrt{\mathrm{n}}}
\end{gathered}
$$

\subsection{Logical Induction}

By means of induction, deduction, analogy, synthesis and other logical analysis methods, this paper has carried on a more in-depth discussion to the information obtained, and demonstrated the correlative relations among various factors of the development of sports industry, as well as the relevant conclusions and suggestions. 


\section{Analysis of Findings}

\subsection{Sports Industry Output and Growth}

Table1.Total output and added value of national and provincial sports industry

\begin{tabular}{|c|c|c|c|c|}
\hline & Total amount $(100$ million yuan) & \multicolumn{2}{c|}{ Structure(\%) } \\
\hline & Total output & Value added & Total output & Value added \\
\hline National Sports Industry & 21984.6 & 7815.9 & 100 & 100 \\
\hline $\begin{array}{c}\text { National Sports Manufacturing } \\
\text { Industry }\end{array}$ & 13517.6 & 3268.9 & 60.7 & 42.3 \\
\hline Sports industry of some province & 2354.09 & 789.4 & 100 & 100 \\
\hline $\begin{array}{c}\text { Sports manufacturing industry in } \\
\text { a province }\end{array}$ & 1141.53 & 217.46 & 48.7 & 27.9 \\
\hline
\end{tabular}

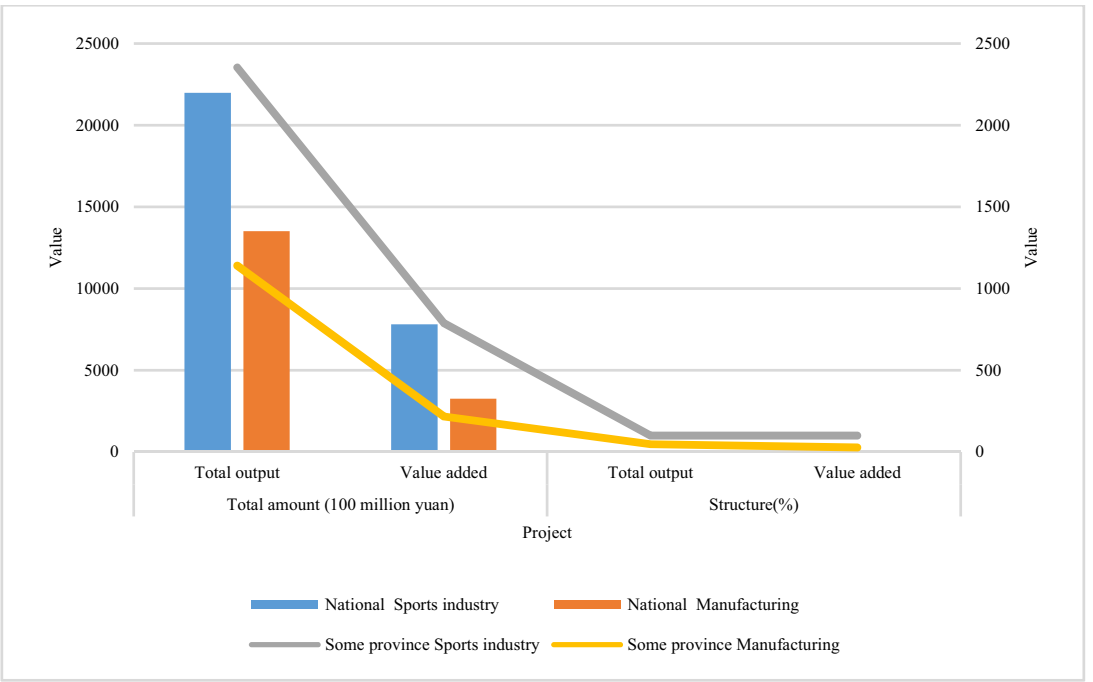

Fig.1. Total output and added value of national and provincial sports industry

As shown in Table 1 and Figure 1, the total output of the national sports industry was nearly 2.2 trillion yuan, with an added value of 781.59 billion yuan. The total output of the national sports goods and related industries was $1,351.76$ billion yuan, accounting for 60.7 percent of the total output of the national sports industry. It can be seen that the manufacturing of national sporting goods and related industries accounts for the largest proportion in the national sports industry. The total output of sports industry in a province was 235.409 billion yuan, and the added value was 78.94 billion yuan. It can be seen that the total output of sports industry in certain province plays an important role in the total output of national sports industry. The total output of sports goods and related industries in a certain province was 114.153 billion yuan, accounting for $48.7 \%$ of the total output of sports industries in a certain province. It can be seen that sports goods and related manufacturing industries in a province account for the largest proportion in the sports industry. In general, the sports goods manufacturing industry in $\mathrm{X}$ province accounts for the largest proportion in the whole sports industry and maintains a good momentum of development.

\subsection{Sports Lottery}

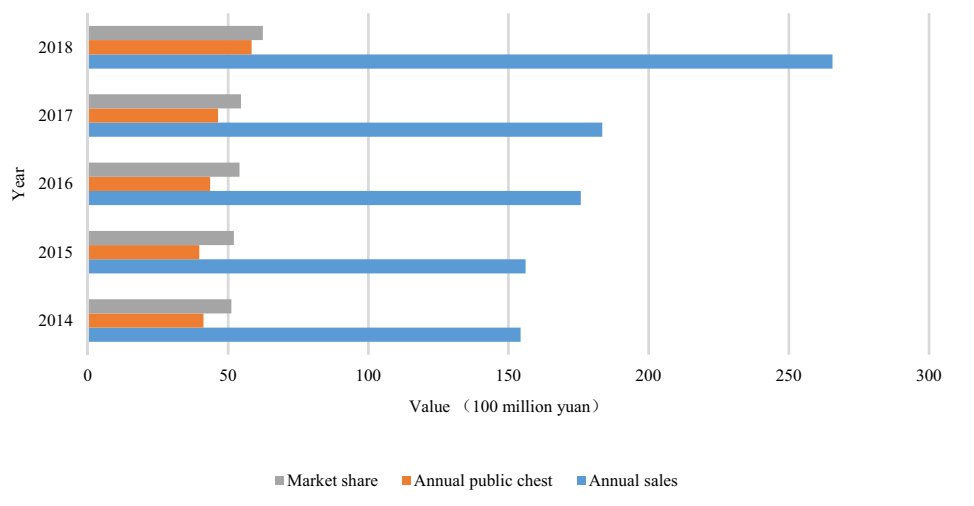

Fig.2. Sports lottery sales, public welfare funds, market share in a province 
As shown in Figure 2, the overall sales volume of sports lottery in a province from 2014 to 2018 showed a trend of steady and progressive development. The annual sales volume basically increased steadily year by year, and the annual public welfare fund generally maintained a steady growth, with all the market shares above 50\%. Among them, in 2018, the annual sales of sports lottery in a province exceeded 25 billion, ranking at the forefront of the country, and the market share reached $62.38 \%$. The World Cup in Russia played an important role in promoting the sales. It can be seen from this that when a closely watched sporting event collides with the relevant culture, there will be certain economic sparks.

\section{Conclusions}

This paper studies and investigates the development of traditional sports industrialization and informatization in China. The results show that the main factors affecting the development of sports industry are as follows: The overall level of economic development, the municipal government's competent departments' investment in the sports industry, the adjustment and innovation of the municipal industrial structure, the citizens' awareness of sports health and sports consumption, the situation of the fitness sports venues meeting the citizens' sports requirements, etc. The internal connection between informationization and traditional sports provides profound enlightenment for its industrialization. On the one hand, it is beneficial to break the traditional development mode of traditional sports and provide a new development concept for its industrialization development. On the other hand, the use of informationization can maximize the inheritance and protection of traditional sports and expand its development space. Nowadays, it is a trend that information economy is over applied to sports industry. The promotion of information economy to sports industry is conducive to arouse people's awareness of developing the industrialization of traditional sports and enrich its development means.

\section{References}

1. Cao K. Design and implementation of Internet plus mode in sports training and monitoring[J]. Revista de la Facultad de Ingenieria, 32,16:811-817, (2017)
2. Branscombe N R, Wann D L. The Positive Social and Self Concept Consequences of Sports Team Identification[J]. Journal of Sport \& Social Issues, 15,2:115-127, (2016)

3. Li W. Application of cloud computing in informatization of physical education teaching resources[J]. Revista de la Facultad de Ingenieria, 32,11:626-631, (2017)

4. Zhang Z, Min H. Analysis on the Construction of Personalized Physical Education Teaching System Based on a Cloud Computing Platform[J]. Wireless Communications and Mobile Computing, 2020,3:1-8., (2020)

5. Hwang J J. China's Military Reform: The Strategic Support Force, Non-Traditional Warfare, and the Impact on Cross-Strait Security[J]. Issues \& Studies, 53,03:19-111, (2018)

6. Filenko L, Ashanin V, Basenko O, et al. Teaching and learning informatization at the universities of physical culture[J]. Journal of Physical Education and Sport, 17,4:2454-2461, (2017)

7. Khoryniak V. MOTIVATION AS ONE OF THE FACTORS OF PROMOTING THE DEVELOPMENT OF PERSONNEL[J]. Regional'ni aspekti rozvitku produktivnih sil Ukraïni, 22:113-124, (2017)

8. Zhang R L, He W, Chen M Y. A study of market segmentation among adolescent consumers of Action Sports $[\mathrm{J}]$. Asian Sports Management Review,10:11-24, (2016)

9. Ahmet A. The analysis on sport attitudes of students at high school education in Turkey[J]. Educational Research and Reviews, 11,5:194-203, (2016)

10. Shiota K, Tokui A. Factors Affecting Volunteer participation in sport for the disabled[J]. Taiikugaku Kenkyu, 61,1:149-158, 2016

11. Hildingsson $M$, Fitzgerald $U \mathrm{~T}$, Alricsson $\mathrm{M}$. Perceived motivational factors for female football players during rehabilitation after sports injury - a qualitative interview study[J]. Journal of Exercise Rehabilitation, 14,2:199-206, 2018

12. Guerreiro J, Rita P, D Trigueiros. A Text Mining-Based Review of Cause-Related Marketing Literature $[\mathrm{J}]$. Journal of Business Ethics, 139,1:111-128, (2016) 